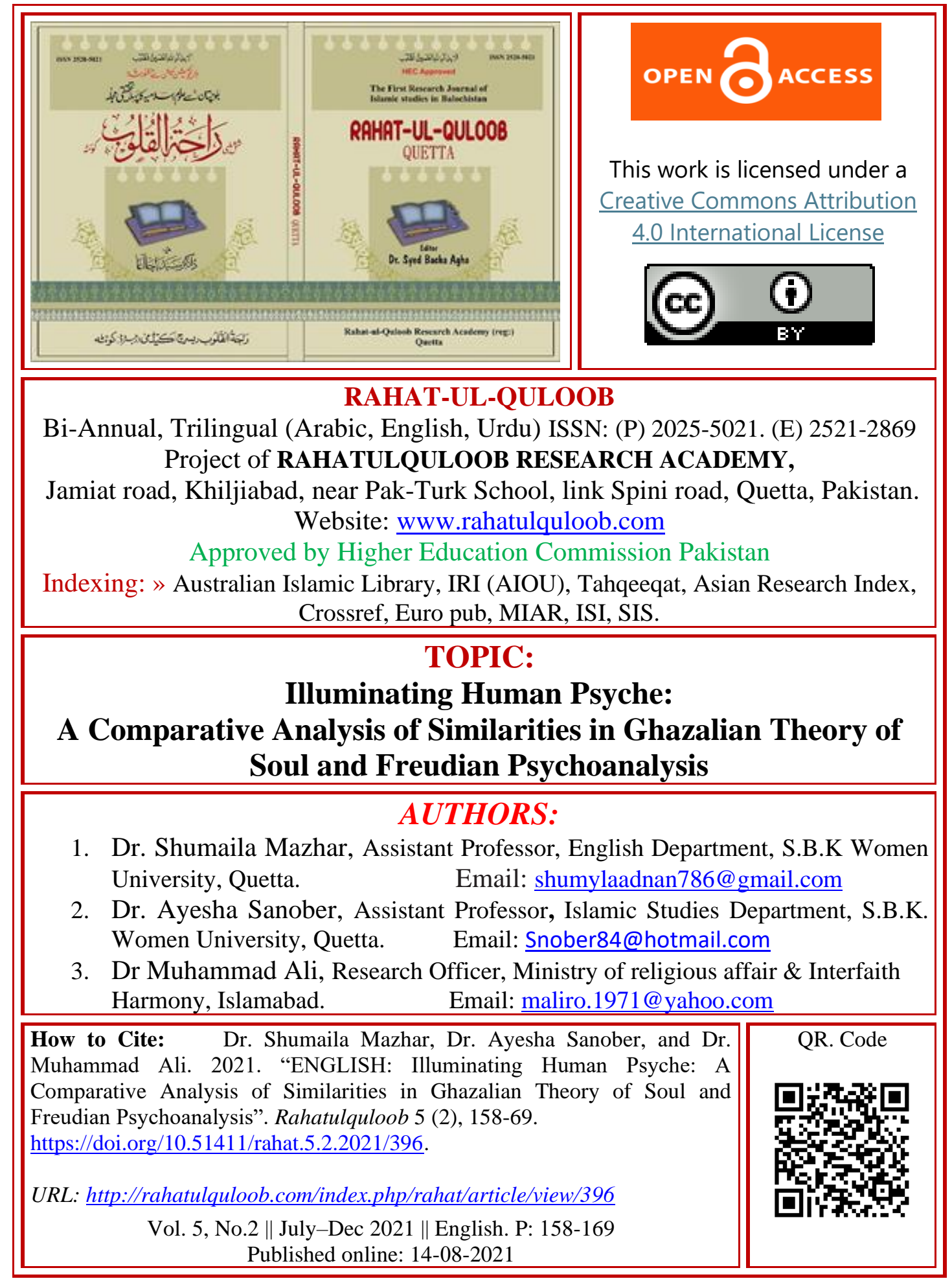




\title{
Illuminating Human Psyche: A Comparative Analysis of Similarities in Ghazalian Theory of Soul and Freudian Psychoanalysis
}

\author{
${ }^{1}$ Shumaila Mazhar, ${ }^{2}$ Ayesha Sanober, ${ }^{3}$ Muhammad Ali
}

\begin{abstract}
:
There have been several theories in the Western world, highlighting various features of human mind, but none of them seems to present the whole truth. The richness and diverse outlook of human experience makes it imperative to look for a model, which contributes in better and all-encompassing understanding of human nature. The present study intends to provide the venue to the spiritual insights of Ghazalian thought to be incorporated into the study of Freudian psychoanalysis, with its central focus on the similarities between them. Besides the current study proceeds from the assumption that though Freudian psychonalytic theory has provided insightful psychological interpretations, equally appropriate readings result from analyzing Ghazalian theory of soul. This study follows the descriptive and analytic methodology to investigate the similarities in both the models and has been developed according to the guidelines provided by Zepetnek's (1998) theory of comparative literature. This analytical approach may lead to an alternative critical agenda for the better understanding of human psyche. In addition, it is also hoped that the insights yielded by this research study may develop into new forms of understanding in the realm of psychology.
\end{abstract}

Keywords: Mind, soul, psyche, nafs.

Introduction:

The functioning of human mind has been a topic of perpetual interest to man since time immemorial. There have been a vast array of poets, writers, philosophers and psychologists who have struggled to interpret it. The immensely complex phenolmena in human beings is nature, which can be approached through several ways. In recent years, there has been a renewed interest in the critical analysis of the Western worldview which inclines to study man in a highly-compartmentalized manner, considering him fundamentally as a material being. In trying to gain a deeper understanding of human nature, Western psychological theories have tended to focus on one aspect of the self (e.g., psychoanalysis focuses on the conscious/unconscious mind, cognitive psychology focuses on thoughts, and behavioral psychology focuses on human behavior), emphasizing more on the biological and psychical dimensions of an individual, sometimes ignoring the metaphysical side of human nature. ${ }^{1}$ Consequently, the spiritual entity in man is either less recognized or simply dismissed completely. For this reason, several attempts have been made by social scientists who recognize the need to understand personality and human psychology from a more holistic perspective, concluding that the spiritual component of man is too vital to overlook with regard to human psychological and personality studies. ${ }^{2}$ 
In brief, this entire development has increased our knowledge about what religion articulates about human psyche, its origin and development. However, due to the assertion that religious ideology regarding human psyche lacks empirical substantiation, there still exists lesser interest in this area of study. Though this seems to be a valid concern on the part of researchers, yet there is no denying that some of the most prominent theories in psychology (i.e., personality and clinical psycho-logy) are far from being scientifically based. ${ }^{3}$ Moreover, a huge treasure of religious teachings and wisdom that have exerted a tremendous impact on the thoughts, behaviors and attitudes of myriad generations of people, need to be considered worthy of attention while studying human psyche. Hence, psycholo-gical frameworks, provided by influential religious scholars, should be given due attention as a valid field of investigation.

Thus, the present study intends to provide the venue to the spiritual insights of Ghazalian thought to be incorporated into the study of Freudian psychoanalysis since both the theorists have enriched the world with their innovative and pioneer-ing ideas. Although, these Islamic and Western models offer somewhat similar attitude towards the inner workings of human mind, yet the major concern of the present study is to examine the variances in their philosophical underpinnings.

\section{Conceptual Underpinnings of the Study:}

The basis of theoretical framework for the present study is the theories propounded by Ghazali and Freud, whose ideas, regarding the intricacies of human mind are greatly connected. If, in the West, Sigmund Freud has enriched the world with his psychoanalytic theories; in the Eastern world, there have been various approaches that render great help in understanding an individual's personality. Among them, Ghazalian theory of soul expounds, in very clear terms, a distinct concept of individual growth and development. Since Ghazali's theory of soul is founded on the teachings of Quran, ${ }^{4}$ so it runs parallel to his conception of God. A significant feature of Ghazalian thought is its concept of the illumination of the divine light within soul. Ghazali sees human nature in its "relation of unity with God, from whom it receives its inner light". Accordingly, in Ghazali, the detailed study of human behaviour requires a profound analysis of human soul. Ghazali, as a true knower of human psychology, embarked on the task of examining the real psychological nature of man and discovered the existence of two peculiar tendencies in human nature, one that incites a person towards evil and produces such qualities like "impurity, deceit, deception, treachery". 6 The second tendency is divine and produces good qualities such as "wisdom, knowledge, certain faith......pardon, contentment, self-satisfaction, asceticism, piety".? On account of the existence of these two tendencies, three potentialities govern human soul, namely; nafs e ammara,nafs e lawwama and nafs e mutmainna. Time and again Ghazali elaborated the true nature of these human potentialities by stating that if the lower self or nafs e ammara gets stronger, it makes the divine elements of human soul subject to evil, which affect his behavior and action. On the contrary, if the divine elements of nafs al-lawwama get strong hold by becoming highly conscious of 
God, the evil elements yield to goodness. In this way, evil elements are substituted with goodness, and it finally culminates in the tranquil state of mind or nafs $e$ mutmainna. ${ }^{8}$

In the similar vein, the psychoanalytic discovery of Sigmund Freud, the father of psychoanalysis, in the realm of unconscious, heralded the beginning of modern psychology as one of the intellectual milestones of the $20^{\text {th }}$ century. ${ }^{9}$ Freudian dynamic view on human mind, encompassing its three structures - the id, ego and superegoopened new vistas of understanding and insights into modern psychology. In the first phase, it was through his most influential work Interpretation of Dreams (1900), Freud presented his vehement arguments on the existence of the unconscious, hidden below the conscious. ${ }^{10}$ In the second phase of psychoanalysis, Freud improvised his topographical model and introduced his structural model using terms like $i d$, ego and superego. For the first time, he gave voice to this model in his essay Beyond the Pleasure Principle in 1920. The entities of $i d$, ego and superego were not separate regions that divide human mind, rather they had been employed by Freud as theoretical constructs, describing various functions of human mind. In 1923, Freud provided a more detailed explanation on the working of human mind in his essay The Ego and the Id. Freudian explanation of $i d$ refers to that dark and inaccessible part of human mind which comprises raw forces and represents elemental drives. ${ }^{11}$ It is the "biological and instinctual" part of human personality. ${ }^{12}$ In order to satisfy the basic instincts under pleasure principle, id transforms the biological needs into psychological tensions. At the time of birth, these inner forces have not been influenced by the external world, so they remain unsocialized. ${ }^{13}$ The hidden forces present in idare driven by the pleasure principle, which tend to strive for the immediate gratification of its instincts "to survive and reproduce". ${ }^{14} I d$ represents forces which result in behavior, generally considered destructive by the majority of a civilized population. ${ }^{15}$ Although Ego has multiple meanings depending on both theoretical and cultural contexts, but this study will use Freudian's descriptions only. He views ego as a protective, intermediary shield between the $i d$ and the external world. This is the structure of personality that deals with the real world and has been literally termed as the "I". ${ }^{16}$ The demands of $i d$, which merely aim at pleasure gratification, get balanced through ego's attempts of providing appropriate satisfaction. Since ego operates on reality principle and can tolerate pressures built up by the $i d$, it makes our instinctive drives delay gratification till they can be properly fulfilled. ${ }^{17}$ Furthermore, the structure which compels an individual to observe societal rules and helps him shape his personality is termed as superego. It is somewhat similar to the conscience which provides a set of guidelines, inculcating a sense of right and wrong, which develops with the internalization of parental figures. Moreover, certain parts of superego are unconscious because human beings are not always aware of the internalized moral forces that constrain their actions ${ }^{18}$. Freud divides the superego into two parts; the 
ego ideal and conscience. The ego ideal rewards good behavior while conscience punishes the bad one.

\section{Literature Review:}

Theories of mind have long been a question of great interest in a wide range of literary fields. The issues regarding the intricacies of human mind have been raised and discussed by mighty intellectuals of all times. The frequent attempts intended to explore human psyche and mind reveal that it has been an essential concern in almost all ages. Moreover, to construct a better and more comprehend-sive view of human mind is "not to pit the various theories against one another but rather to synthesize across them" 19 Contemporary trends in interdisciplinary theorizing between science and the humanities reveal that the knowledge about human mind can be enhanced, if seemingly discordant viewpoints are brought into dialogue. Thus, the current study is an attempt to explore the variances in the theories propounded by Ghazali and Freud, the two mighty minds of the world.

Ghazali's immense intellectual stature is well recognized in literature, yet very little is known about the contributions of Ghazali, one of the several Arab-Islamic precursors of medieval Europe's Latin Scholastics, who wrote extensively on human psychology. ${ }^{20}$ Similarly, he is among the first whose works fascinate the attention of European scholars ${ }^{21}$. Moreover, Ghazali has also been "acclaimed as the greatest . . . certainly one of the greatest" 22 and "by general consent, the most important thinker of medieval Islam". ${ }^{23}$ Ghazali believes in the existence of two fundamental tendencies in human soul $^{24}$; the evil tendency (animalistic), producing vices and the tendency which motivates an individual towards good (angelic). On account of these two peculiar tendencies, ${ }^{25}$ there appear three types of nafs, namely; nafs e ammara (the evil-instigating soul), nafs e lawwama (the reproaching soul), nafs e mutmainna (the contented soul). Moreover, Ghazali has also highlighted the role of $a q^{\prime} l$ in human psyche which plays the dynamic role of reason.

Turning now towards Sigmund Freud, the father of psychoanalysis, it has been found that his discovery in the realm of unconscious and the development of the scientific inquiry of psychoanalysis, heralded the beginning of modern psychology as one of the intellectual milestones of the $20^{\text {th }}$ century ${ }^{26}$. In the history of human civilization, Freudian theories regarding human mind have a huge impact in the realm of scientific, intellectual and cultural thought, despite the fact that many agree ${ }^{27}$ and some disagree ${ }^{28}$. Although the genuineness of Freudian metapsychology remains debatable, yet Freudian theory encompasses a huge corpus of concepts which continues to exercise a deep impact on 20th century. ${ }^{29}$ He has been consi-dered as one of the greatest explorers of the human mind that ever lived. ${ }^{30}$

Freudian dynamic view on human mind, encompassing its three structures - the $i d$, ego and superego - opened new vistas of understanding and insights into modern psychology. However, despite this reputation of psychoanalysis, there remains a paucity of evidence on its scientific nature. More recently, literature has emerged that 
offers contradictory findings about psychoanalytic approach. This approach denotes a combination of scientific and non-scientific because Freud hardly ever gave "operational definition of his theoretical constructs of id, ego and superego" so the final verdict might be given in favour of his approach being unscientific ${ }^{31}$.

The present study is based on the assumption that the spiritual insights of religion may offer distinctive potential to the field of psychological studies. Currently, this can be seen in such contemporary movements such as transpersonal psychology, which aims at directly incorporating a spiritual component to psychological coun-seling. An evidence, in support of this argument, can be found in a discussion on the subject when he mentions that psychoanalysis in its "skeptical denial of trans-cendence, has turned its back on the possibility of transcendence", while transper-sonal psychology has an "enthusiasm for transcendence". ${ }^{32}$ Increasingly, in the west, there is a trend of incorporating the insights, beliefs and spiritual doctrines of nonwestern traditions, especially Buddhism and eastern philosophy, to the practice of modern psychology. Though the spiritual dimension finds least attention by the followers of modern psychology, yet the American Psychological Association recognizes religious psychology as a separate field in modern psychology ${ }^{33}$. Foundational to this, is the drastic change in the whole scenario that the last two decades witnessed. Initially, Christian models were focused exclusively, but later on, a widespread interest has been felt in research studies highlighting Muslim ${ }^{34}$, Jewish ${ }^{35}$ and Hindu models ${ }^{36}$. As a result, it might safely be asserted that the new field of the psychology of religion has emerged as a legitimate area of research. ${ }^{37}$

\section{Method of Comparative Study:}

This research study has been developed according to the guidelines provided by Zepetnek's (1998) theory of comparative literature. Since this study deals with the similiraties present in the theoretical models of Ghazali and Freud on the concept of human mind, Zepetnek's theory proposes an essential structure to meet its requirements. This model fundamentally covers two main aspects of comparative literature. Initially, it outlines the nature of comparative literature, and secondly, it gives ten different principles to be followed in comparative study of literature. According to the first aspect of this model, "Comparative Literature means the knowledge of more than one national language and literature, and/or it means the knowledge and application of other disciplines in and for the study of literature". ${ }^{38}$ The second aspect of Zepetnek's model discusses different principles of the comparative study of literature. These principles include: "method instead of a theory, dialogue between literatures, acquiring in-depth grounding in several literatures, Literature and other forms of artistic expression, comparative conceptual approach and focus on literature within cultural context, ideological inclusion, interdisciplinary study, content against globalization versus localization, and the significance of comparison". ${ }^{39}$ The present study applies the seventh principle of Zepetnek's model for the comparative analysis of variances in Ghazalian and Freudian theories.According to this principle, "Comparative Literature 
is theoretic-cal, methodological as well as ideological and political approach of inclusion". ${ }^{40}$

In this way the successful application of Zepetnek's method of thematic inclusion needs to be based on its being (1) goal-oriented, organized to achieve particular goals (2) reciprocal, given or shown by each of two sides or individuals to the other, (3) based on equal status of both participants, (4) comparative and not influential, no side can influence the other, and (5) both sides maintain their individuality. These are some of the principles which are kept in mind while juxtaposing Ghazali and Freud to find certain variances which may manifestly exist in their theories. Though these theorists belonged to different eras, cultures, languages and religions, they hold certain similar views on the points that define features of the human mind, its role and impact on human life. However, the differences found in their respective views are fundamentally based on their religious beliefs.

\section{Data Analysis:}

Human nature is considered an enormously complex phenomenon in human beings, which has been approached through numerous ways. There exists a huge array of Western theories, attempting to explore the intricacies of human mind, but none of them seems to present the whole truth, on account of their attitude of overlooking the spiritual dimension. Thus, the diverse outlook of human experience makes it imperative to search for a model, which contributes in better and all-inclusive understanding of human nature.

In view of all that has been mentioned so far, it is important to bear in mind that if in the West, Freudian theories render great help in understanding an individual's personality; in the Eastern world, Ghazali has enriched the world with his distinct concept of the growth and development of human mind. Furthermore, a detailed and extensive study of the psychological disposition of human beings' sheds light on the similarities in the theories propounded by Ghazali and Freud. Of paramount significance is the fact that the selected theorists vary in origin, chronological orders, cultural and temporal settings, and are separated by a nine-century gap, they still address similar psychological issues and provide insight regarding, "the most probing inquiry into the dynamics of psychic life". ${ }^{41}$ The universality of the selected theorists strengthens our belief in the similar working of human mind.

\section{Affinities in the Structural, Dynamic and Topographic Models by Ghazali and Freud:}

A close examination of the Freudian and the Ghazalian theory, reveals prominent similarities in "structural and topographic", ${ }^{42}$ dimensions of both the models. Human psyche comprises various structures, each possessing a distinctive and highly-defined functions. Freud considers the three components of personality (i.e., id, ego, superego) constantly functioning in a different direction, which results in psychological conflict and anxiety and a craving for peace of mind ${ }^{43}$. The exact dynamic of $i d$ and superego characterizes nafs e ammara and nafs e lawwama, the evil and celestial components of 
human mind respectively, while Freudian constructs of ego is similar to the Ghazalian concept of $a q^{\prime} l$. Human mind is prone to irrational, primitive behavior, under the influence of nafs e ammara or $i d$, despite the existence of a neutralizing force, i.e., aq'l or ego. So, these conflicting forces, operating on varying levels, cause psychological conflict and anxiety in their desire for mental peace. Besides, both the models are Dynamic which suggests that "there are forces in conflict within the individual and thought, emotion and behavior are the resultants of these conflicting forces". ${ }^{44}$

\section{Similarity between Nafs e Ammara and Id:}

As has been mentioned earlier, Ghazalian nafs e ammara and Freudian id are the strongest forces within human psyche which operate outside the conscious awareness. The behaviour of al-Ammara or evil-instigating soul is the foundation of all longings intensified by appetites and lust, motivating a person to "immediate gratification, irrespective of moral consequences". ${ }^{45}$ If, on one hand it is the "dark, inaccessible part of our personality.... a chaos, a cauldron full of seething excitations"46, on the other hand, Ghazali views it as "evil commanding psyche" 47 , forming the most essential constituent of nafs. Both the theorists agree that the processes of nafs-e-ammara or id are unconscious, its existence can be comprehe-ndded from certain feelings, thoughts and behaviors whose central function is to incite man to evil by breaching the moral boundaries. $^{48}$

Moreover, these forces also comprise prohibited wants and instincts, which are administered by the pleasure principle. The viler aspects of human psyche, including physical and sexual appetites, inclination towards evil and socially undesirable conduct $^{49}$ are the outcome of the forces of nafs e ammara or $i d$, working on the unconscious level. Thus, a detailed analysis of the psychological disposition of the selected characters reveals the universality of Ghazalian nafs e ammara and Freudian $i d$ and the close resemblances between their structure and functions.

\section{Similarity between $A q ' l$ and Ego:}

Ghazali and Freud have shown somewhat similar attitude on various aspects of $a q$ ' $l$ or ego. As both $a q^{\prime} l$ andego are the conscious parts of the psyche, use logical thinking, and mediate between the deep levels of the psyche and the external reality. Freudian ego develops out of modification of the $i d$, playing the role of mediator"between the $i d$ and external reality". ${ }^{50}$ Moreover, ego provides a socially acceptable outlet to the immediate demands of $i d$ which aim at pleasure gratification.

However, Ghazali offers a leading place to the intellect or $a q$ 'l which comprises reason, the capacity to discriminate "right and wrong, good and evil, the real and the illusory, all of which enable man to get nearer to God" 51 . The unique charac-teristic that distinguish a man from animal is $a q^{\prime} l$, which has the potential either to elevate him to the status of angels or debase him to the level of animals. Moreover, as Ghazali highlights, man has been endowed with all faculties for the realization of fitrah which can only be achieved by proper application of $a q^{\prime} l^{52}$. Besides, this reasoning faculty of $a q$ 'l, can only be applied through knowledge.In this way, $a q^{\prime} l$ or ego's use of 
logical thinking, mediates between the deep levels of conscious mind and the external reality. It also provides a socially acceptable outlet to the unrestrained pleasure of nafs e ammara / id and the restraint-seeking attempts of nafs e lawwama or superego by delaying the gratification of instinctive drives until they can be properly fulfilled.

\section{Similarity between Nafs e Lawwama and Superego:}

Ghazalian construct of nafs e lawamma and Freudian superego play the role of the conscience. ${ }^{53}$ They strongly criticize the desires of nafs $e$ ammarah or $i d$, and constitute the ideals that a person attempts to reach. Besides, Freud splits the superego into two parts: "the punitive and the "ego-ideal" aspects. ${ }^{54}$ The punitive aspect of the superego develops out of social norms which reproaches a person and causes feelings of guilt, in case of his yielding to the demands of nafs e ammara / id. It also offers a crucial choice either to change behavior or continue seeking the destructive path of evil inclinations. In contrast, the 'ego-ideal' aspect of the superego characterizes social norms, values or ethical principles, the emotional attachment and respect which helps in socializing man's behavior. ${ }^{55}$

This state of human psyche remains in continuous awareness "scrutinizing, criticizing and self-accusing". ${ }^{56}$ Both Ghazali and Freud agree on the functioning of nafs $e$ lawamma or superego as to inculcate a sense of guilt and regret. The superego is allseeing and its all-pervasive eye makes a distinction between acts and intentions. This strong power develops a feeling of remorse even for those acts which are just envisioned but never carried out.

Moreover, there is a slight difference between Ghazalian concept of nafs e lawamma and Freudian superego. Ghazali considers it in the mid of its journey towards its spiritual evolution and perfection, the highest state which can only be achieved when appetent soul is opposed and driven off, while Freudian model fails to capture this spiritual aspect of superego on account of his secular foundations.

\section{Recommendations and Suggestions:}

Based on the findings of this research, the present study recommends the need for a diverse outlook which may contribute in better and all-inclusive understanding of human nature. Since the modern psychological disorders have led to a reawakening among psychologists to analyze human mind and personality by incorporating a spiritual component, so Ghazalian theory of soul had never been more meaningful to the world as to respond to the moral decay and value crisis of the present atheisticmaterialistic globalization. However, Ghazalian concept of human psyche is not purely psychological, but has great concern with philosophical- metaphysical aspect of human psyche. Besides, it is also noteworthy that the concept of human nature in Ghazalian discourse focused on making an in-depth analysis of the self, with its functions, its absolute purpose, and the factors that bring about its distress and delight. Thus, the present study recommends that although Freudian psychoanalytic theory has provided insightful psychological interpretations, equally appropriate readings result from analyzing Ghazalian theory of soul. Ghazalian theory balances the Freudian 
emphasis on the unconscious. This analytical approach may lead to an alternative critical agenda for the better understanding of human psyche. Besides, it is also hoped that the insights yielded by this research study may develop into new forms of understanding in the realm of psychology.

\section{Conclusion:}

From the above discussion, it can be concluded that though, in the West, important achievements have been made to explore the intricacies of human mind and behavior, yet no single western model is truly comprehensive in itself in providing insight into the interplay between body, mind and soul, and the results of this interplay on human personality development. These major limitations in understanding human mind, raise the questions regarding the extent of human knowledge about self, and the depth of human understanding about personality. Even multiple Western schools of thought have proven limited, as they continue to ignore a dimension of the self that many regard as central to being human, i.e., the spiritual dimension.

Though, Ghazalian theory of soul and Freudian psychoanalysis have developed in utterly different times and in dissimilar social, cultural, and religious frameworks as models of the individual human psyche, but they offer diverse possibilities for the growth and development of human mind. This interdisciplinary study, has established the fact about the similar functioning of human mind, despite the variations in geographical, cultural and religious backgrounds. The rationale behind profound ideological similarities in Ghazali and Freud, is the depth of their psychological experiences and insight into human consciousness.

\section{References:}

${ }^{1}$ Mohammad Yasin, The Islamic Conception of Human Nature with special reference to the Development of an Islamic Psychology. University of Cape Town. (PhD Dissertation) 1986.

${ }^{2}$ Hisham Abu-Raiya. "Toward a systematic Qura'nic theory of personality". Mental Health, Religion \& Culture, 15(3), 2012: 217-233.

${ }^{3}$ ibid

${ }^{4}$ N. Hanif. Biographical Encyclopaedia of Sufis: Central Asia and Middle East. 2. New Delhi: Sarup \& Sons. 2002. ISBN 8176252662, 9788176252669

${ }^{5}$ Harold,Coward. Jung and Eastern Thought. State University of New York Press, USA. 1985.

${ }^{6}$ Abu Hamid Ghazali. Revival of Religious Learning. Ihya-ulum- Udin Book 3. Fazal-ul-Karim. Trans., Muhammad Ashraf, Lahore. 1993.

${ }^{7}$ ibid

${ }^{8}$ Abu Hamid, Ghazali. Kimyâ-yı Saadet Kimiya-e Saadat-The Alchemy of Happiness.The Other Press. 2000. ISBN 9839154958, 9789839154955.

${ }^{9}$ Jeffrey Schwartz \& Sharon Begley. The mind and the brain: Neuroplasticity and the power of mental force. New York, NY: Harper Collins .2002.

${ }^{10} \mathrm{Jim}$ McMartin. Personality Psychology: A Student-Centered Approach. New Delhi: SAGE Publications.1995.

${ }^{11}$ Robert, Harper. Psychoanalysis and Psychotherapy. A Spectrum Book Prentice Hall, U.S.A. Harvard University Press. 1959. ISBN 0674323351, 9780674323353 
${ }^{12} \mathrm{Jim}$ McMartin. Personality Psychology: A Student-Centered Approach. New Delhi: SAGE Publications.1995.

${ }^{13}$ Howard S. Friedman \&, Miriam W. Schustack. Personality, Classic Theories and Modern Research. Allyn \& Bacon. USA. 1999.

${ }^{14}$ Mayers, Ozzie. The Power of the Pin: Sewing as an Act of Rootedness. American Literature. College English. 1988.

${ }^{15}$ Jack, Boozer. Religion, the Id, and the Superego. Journal of Bible and Religion. 3(28), 323-328: 1960. Oxford University Press.

${ }^{16}$ Howard S. Friedman \&, Miriam W. Schustack. Personality, Classic Theories and Modern Research. Allyn \& Bacon. USA. 1999.

${ }^{17} \mathrm{Jim}$ McMartin. Personality Psychology: A Student-Centered Approach. New Delhi: SAGE Publications.1995.

18 ibid

${ }^{19}$ Joseph, LeDoux. Synaptic self: How our brains become who we are. New York: Penguin Books. 2002.

${ }^{20}$ S.M. Ghazanfar. The Economic Thought of Abu Hamid Al-Ghazali and St. Thomas Aquinas: Some Comparative Parallels and Links; History of Political Economy. Duke University Press. 1993.

${ }^{21}$ Margaret Smith.Al-Ghazali, the Mystic: A Study of the Life and Personality of Abū Hāmid Muhammad Al-Tūsī Al-Ghazāl: Luzac\& Company. London. 1944.

${ }^{22}$ W.Montgomery Watt. The Faith and Practice of Al Ghazali. One world Publications. England. 1953.

${ }^{23}$ F.R.Bagley. Introduction to Nasihat al Muluk, by Abu Hamid Al-Ghazali. NewYork and London: Oxford University Press. 1964.

${ }^{24}$ Hisham Abu-Raiya. “Toward a systematic Qura'nic theory of personality”. Mental Health, Religion \& Culture, 15(3), 2012: 217-233.

${ }^{25}$ Amber, Haque."Psychology from Islamic perspective: Contributions of early Muslim scholars and challenges to contemporary Muslim psychologists". Journal of Religion \& Health. 43, 2004: 357-377.

${ }^{26}$ Schwartz, L., \& Solomon, P. Psychoanalysis: Chapter 31, In Handbook of Psychiatry, P. Solomon and V. Patch (eds.). Los Altos: Lange Medical Publications. 1974. 489-522.

${ }^{27}$ Gerald, Edelman. Bright Air, Brilliant Fire: On the Matter of The Mind. Basic Books. 1992. ISBN 0465007643, 9780465007646.

${ }^{28}$ McCrone, J. Freud's neurology. Lancet Neurology, 2004. 3, 320

${ }^{29}$ Richard, Askay \& Jenson, Farquhar. Apprehending the Inaccessible: Freudian Psychoanalysis \& Existential phenomenology. Northwestern University Press, Evanston, Illinois. 2006.

${ }^{30}$ Peter, Gay. Freud: a life for our time. Doubleday Anchor books. University of California. 1989.

${ }^{31}$ Michael, Eysenck. Perspectives on Psychology. Psychology Press. Taylor and Francis Group, New York .2013. 112-113.

${ }^{32}$ Washburn, M. Transpersonal Psychology in Psychoanalytic Perspective. State University of New York Press, Albany. 1994.

${ }^{33}$ Achoui, M. (Human Nature from a Comparative Psychological Perspective, The American Journal of Islamic Social Sciences. 15(4). 1998: 71-96

${ }^{34}$ Ghorbani, N., \& Watson, P.J Religious orientation types in Iranian Muslims: Differences in alexithymia, emotional intelligence, self-consciousness and psychological adjustment. 2006. Review of Religious Research, 47(3), 303-310.

${ }^{35}$ David H. RosmarinRosmarin, D. H., \& Pargament, K. I., \& Krumrei, E. J., \& Flannelly, K. J. Religious coping among Jews: Development and initial validation of the JCOPE. Journal of Clinical Psycholog. 2009. 65(7), 670-683. 
${ }^{36}$ Tarakeshwar, Nalini; Pargament, Kenneth I.; Mahoney, Annette. Measures of Hindu pathways: Development and preliminary evidence of reliability and validity. Culture Diversity and Ethnic Minority Psychology. 2003. 9, 316-332.

${ }^{37}$ Ralph W. Hood, Jr., Peter C. Hill, and Bernard Spilka. (2009). The psychology of religion: An empirical approach (5th ed.). 2009. New York: Guilford Press.

${ }^{38}$ Steven Tötösy de Zepetnek. Comparative Literature: Theory, Method, Application. Amsterdam / Atlanta: Rodopi, 1998.

${ }^{39}$ ibid

${ }^{40}$ ibid

${ }^{41}$ Peter, Brooks.Reading for the Plot, Designs and Intentions in Narrative. Clarendon Press Oxford. 1984.

${ }^{42}$ Hisham Abu-Raiya. "Toward a systematic Qura'nic theory of personality". Mental Health, Religion \& Culture, 15(3), 2012: 217-233.

${ }^{43}$ Sigmund, Freud. Group Psychology and the Analysis of the Ego. In Sigmund Freud's Civilization and its Discontents and Other Works. J. Strachey et al (eds.), 1985. 12, London: Penguin Books:91178.

${ }^{44}$ Irvin D. Yalom. Existential psychotherapy. New York: Basic Books. 1980.

${ }^{45}$ Ansari Ahmad. Qur'anicconcepts of human psyche. In Zafar A. A. (Ed)), Islamabad: International Institute of Islamic Thought and Institute of Islamic Culture. 1992. ISBN 9694620031, 9789694620039

${ }^{46}$ Sigmund, Freud, S. The New Introductory Lectures on Psychoanalysis. New York: W.W. Norton and Co., Inc. 1933.

${ }^{47}$ Hisham Abu-Raiya. "Toward a systematic Qura'nic theory of personality". Mental Health, Religion \& Culture, 15(3), 2012: 217-233.

${ }^{48}$ Zohreh, Khosravi. (2006). Towards an Islamic Psychology: An Introduction to Remove Theoretical Barriers. Psychological Studies. Faculty of Education and Psychology. Al-Zahra University.2006.1(4 \& 5):161-172.

${ }^{49}$ RobertSmither,, \&Aleriza Khorsandi, A. The Implicit Personality Theory of Islam. Psychology of Religion and Spirituality, 1(2),81-96. 2009.

of Quran to Contemporary Psychologists. International Research Jurnal of Applied and Basic Sciences, 6(11), 1590-1595.ISSN 2251-838X

${ }^{50}$ Robert Allen Harper. Psychoanalysis and Psychotherapy. A Spectrum Book Prentice Hall, U.S.A. Harvard University Press. 1959. ISBN 0674323351, 9780674323353

${ }^{51}$ FrithjofSchuon. Sufism: Veil and Quintessence- A New Translation with Selected Letters, World Wisdom. 2006. ISBN:1-933316-28-41.

${ }^{52}$ Nooraini Othman. A Preface to the Islamic Personality Psychology: International Journals of Psychological Studies, 8(1),2016. ISSN 1918-7211 E-ISSN 1918-722X

${ }^{53}$ RobertSmither, \&Aleriza Khorsandi, A. The Implicit Personality Theory of Islam. Psychology of Religion and Spirituality, 1(2),81-96. 2009.

${ }^{54}$ Schwartz, L., \& Solomon, P. Psychoanalysis: Chapter 31, In Handbook of Psychiatry, P. Solomon and V. Patch (eds.). Los Altos: Lange Medical Publications. 1974. 489-522.

${ }^{55}$ ibid

${ }^{56}$ Zohreh, Khosravi. (2006). Towards an Islamic Psychology: An Introduction to Remove Theoretical Barriers. Psychological Studies. Faculty of Education and Psychology. Al-Zahra University.2006.1(4 \& 5):161-172. 